\title{
Tamanho de amostra para avaliação de caracteres de cenoura em siste- mas de cultivo agroecológico
}

\author{
Giovani Olegário da Silva; Jairo V Vieira; Michelle S Villela \\ Embrapa Hortaliças, C. Postal 218, 70359-970 Brasília-DF; olegario@cnph.embrapa.br
}

\begin{abstract}
RESUMO
O correto dimensionamento de experimentos deve ser utilizado para que se possa reduzir o erro experimental e com isso, maximizar a precisão das informações obtidas. O objetivo deste trabalho foi estimar o número mínimo de famílias e de plantas por parcela para avaliação de caracteres de raiz em uma população de cenoura cultivada em sistema agroecológico. Os ensaios foram conduzidos no verão de 2006/2007 em duas propriedades com cultivo agroecológico em Brasília: Associação Mokiti Okada, que segue modelo de Agricultura Natural em Brazlândia-DF e Núcleo Rural Taguatinga, seguindo modelo de Agricultura Orgânica em Taguatinga-DF. Foram avaliadas 100 famílias de meio-irmãos de cenoura dispostas em delineamento de blocos casualizados com duas repetições e parcelas de $1 \mathrm{~m}^{2}$. Foram colhidas 20 plantas competitivas por parcela e avaliadas individualmente para os caracteres comprimento de raiz, diâmetro da raiz, massa da raiz, diâmetro do xilema da raiz, relação diâmetro do xilema/ diâmetro da raiz, tipo de ponta da raiz, tipo de ombro da raiz, parâmetro $\mathrm{a}^{*}$ para os tecidos xilema e floema. Foi realizada análise de variância conjunta e para cada sistema, com informação entre e dentro de parcelas. Foram realizadas ainda análises de representatividade do número mínimo de famílias e de plantas para representar uma população de cenoura. Foi verificado que uma amostra de 18 plantas competitivas/parcela coletadas em ensaios com 2 repetições, bem como de 74 famílias, são suficientes para garantir uma adequada avaliação de famílias meio-irmãos de cenoura para os caracteres estudados.
\end{abstract}

Palavras-chave: Daucus carota L., número mínimo de plantas, número mínimo de famílias, simulação.

\begin{abstract}
Sample size for evaluation of carrot traits in agroecologic cultivation systems

The correct experiment design should be used to reduce the experimental error and, with that, maximize the precision of the information obtained. The objective of this work was to estimate the minimum number of families and of plants per plot for evaluation of root traits in a carrot population cultivated in agroecologic systems. The essays were conducted in the summer of 2006/2007 in two agroecologic properties in Brasília: "Associação Mokiti Okada", which follows model of Natural Agriculture in Brazlândia and "Núcleo Rural Taguatinga", following model of Organic Agriculture in Taguatinga, Brazil. We evaluated 100 half-sib families of carrot arranged in randomized block design with two replications and plots of $1 \mathrm{~m}^{2}$. Twenty competitive plants per plot were harvested and individually evaluated for the traits: root length, root diameter, root mass, root xylem diameter, relationship of xylem diameter/root diameter, type of root tip, type of root shoulder, parameter $a^{*}$ of root xylem and phloem. Joint variance analysis of the group and of each system, were performed with information between and inside plots. Analyses of representativity minimum number of families and of plants to represent a carrot population were performed. A sample of 18 plants competitive/plot collected in essays with 2 replications, as well as 74 families, are enough to guarantee an appropriate evaluation of carrot half-sib families for the traits studied.
\end{abstract}

Keywords: Daucus carota L., minimun number of plants, minimun number of families, simulation.

\section{(Recebido para publicação em 21 de maio de 2008; aceito em 11 de maio de 2009)} (Received in May 21, 2008; accepted in May 11, 2009)

\begin{abstract}
A cenoura é uma das principais hortaliças cultivadas no Brasil, sendo que a maioria das cultivares para o cultivo de verão é oriunda de atividades de melhoramento executadas por instituições brasileiras públicas ou privadas. Entretanto, pouca informação tem sido registrada sobre os detalhes metodológicos aplicados durante o processo de desenvolvimento dessas cultivares (Vieira et al., 2006).

$\mathrm{O}$ correto dimensionamento de experimentos deve ser realizado para que se possa reduzir o erro experimental e, com isso, maximizar a precisão das informações obtidas em um experimento (Steel \& Torrie, 1960). Nos programas
\end{abstract}

de melhoramento, a diminuição do erro experimental em função do número de plantas por parcela é de grande interesse, uma vez que conduz a redução da variância fenotípica, e, consequentemente, para maiores progressos genéticos com a seleção (Eberhart, 1970). Estudos sobre tamanho de parcela têm contribuído sobremaneira para a redução de recursos financeiros empregados na pesquisa de várias culturas (Freitas et al., 2001).

Em um mesmo ambiente a máxima exatidão das estimativas genéticas é obtida com o mais elevado número de famílias avaliadas numa população. No entanto, se considerar um experimento em que o número de repetições e de plantas dentro de família é adequado para reduzir a influência ambiental e representar de forma adequada determinado cruzamento, a utilização de um número de famílias suficiente para bem representar determinado cruzamento, é recomendado (Granate et al., 2001). Além disso, o tamanho e número de parcelas está diretamente ligado ao custo de implantação de experimentos e das avaliações, sendo que o balanço entre custo e precisão determina o tamanho ótimo da amostra experimental (Zhanga et al., 1994. Storck et al., 2006).

De acordo com Wu et al. (1978), para fins de melhoramento genético, o tama- 
nho mínimo da amostra pode ser definido como o número mínimo de elementos necessários para estimar a média e a variância de um dos caracteres da população, com precisão razoável.

O tamanho mínimo da amostra de trabalho em melhoramento depende da espécie, do tipo de população, das inferências que se deseja realizar, das condições ambientais sob as quais é conduzida a população e do nível de precisão desejado (Graybill \& Kneebone, 1959; Palomino et al., 2000; Viana et al., 2002, Alves \& Seraphin, 2004), sendo importante que os programas de melhoramento realizem estudos sobre as condições locais em que é aplicada a seleção.

Pelo aumento do interesse por produtos com baixo nível de resíduos de agrotóxicos e produção menos agressiva ao meio ambiente, a agricultura agroecológica tem tido crescimento acelerado em todo o mundo. Considerando-se que a agroecologia representa um conjunto de técnicas e conceitos que visam a produção de alimentos mais saudáveis e naturais, as linhas agroecológicas mais relevantes são: Agricultura Orgânica, Agricultura Biodinâmica, Agricultura Biológica, Agricultura Ecológica, Agricultura Natural e a Permacultura (Souza, 2006).

A Agricultura Orgânica foi fundada em 1931 na Índia, por Sir Albert Howard e por Lady Eve Balfour. A principal característica deste movimento é o processo 'Indore' de compostagem, que se caracteriza por uma compostagem em pilhas ou leiras a céu aberto, as quais são removidas por processo manual. Howard admite que "a verdadeira fertilidade dos solos deve estar assentada sobre um amplo suprimento de matéria orgânica e principalmente na manutenção de elevados níveis de húmus no solo". Neste sistema, o uso de plantas de raízes profundas é ainda recomendado por serem capazes de explorar as reservas minerais dos solos (Souza, 2006).

A Agricultura Natural surgiu no Japão em 1935 e seu fundador foi Mokiti Okada. Ele propôs um sistema de produção agrícola que tomasse a natureza como modelo. Nesse sistema o solo não deve ser movimentado, todos os restos culturais e palhadas devem ser reciclados e não devem ser utilizados estercos animais nos compostos. Atualmente, utilizam-se também microrganismos efetivos (EM), que servem para prevenção de problemas fitossanitários ou na inoculação do composto orgânico que será utilizado na propriedade (Souza, 2006).

O objetivo deste trabalho foi estimar o número mínimo de famílias de meioirmãos e de plantas por parcela para avaliação de caracteres de raiz em uma população de cenoura cultivada em sistemas agroecológicos.

\section{MATERIAL E MÉTODOS}

Os ensaios foram conduzidos no verão de 2006/2007, em duas propriedades com cultivo agroecológico em Brasília: Associação Mokiti Okada, que utiliza modelo de Agricultura Natural em Brazlândia-DF; e Núcleo Rural Taguatinga, seguindo modelo de Agricultura Orgânica em Taguatinga-DF. Os tratos culturais foram efetuados de acordo com os procedimentos usuais de cada propriedade, seguindo as orientações dos respectivos modelos agroecológicos. Foram avaliadas 100 famílias de meio-irmãos de cenoura oriundas de uma população derivada da cultivar Alvorada do programa de melhoramento da Embrapa Hortaliças, obtida por seleção recorrente entre e dentro de famílias de meios-irmãos. As famílias foram dispostas em delineamento de blocos casualizados com duas repetições e parcelas de $1 \mathrm{~m}^{2}$. A semeadura foi feita em quatro linhas transversais ao comprimento do canteiro, espaçadas de $25 \mathrm{~cm}$ uma da outra, totalizando aproximadamente cerca de 100 plantas por $\mathrm{m}^{2}$. $\mathrm{O}$ desbaste nas duas propriedades foi realizado 30 dias após semeio; na primeira propriedade foi cultivada uma planta a cada $2 \mathrm{~cm}$, sendo que na segunda propriedade o desbaste foi apenas parcial (apenas retirado o excesso de plantas), a metodologia de cultivo empregada, inclusive do desbaste, foi a utilizada tradicionalmente nos diferentes modelos agroecológicos.

Foram colhidas 20 plantas competitivas por parcela com aproximadamente 90 dias após semeio, as quais foram avaliadas individualmente para os caracteres comprimento de raiz (mm), diâmetro da raiz (mm) avaliado na metade do comprimento da mesma, massa da raiz (g), diâmetro do xilema da raiz $(\mathrm{mm})$ avaliado na metade do comprimento da raiz, relação diâmetro do xilema/diâmetro da raiz, tipo de ponta da raiz (critério de notas: $1=$ arredondada, $2=$ levemente afilada, $3=$ afilada), tipo de ombro da raiz (critério de notas: $1=$ cônico, $2=$ arredondado, 3=plano, 4=côncavo), e por leitura colorimétrica direta, determinou-se o parâmetro $\mathrm{a}^{*}$ para os tecidos xilema e floema de cada raiz, utilizando-se o analisador de cor de tristimulus compacto Minolta CR-200b (Minolta Corporation Instrument System Division), parâmetro de cor que determina o teor de â-caroteno das raízes de cenoura (Pereira, 2002).

Os dados foram submetidos à análise de homogeneidade de variância (teste de Bartllet) e de normalidade (Lilliefors) para cada sistema individualmente, e de homogeneidade de variância na análise conjunta. Os caracteres parâmetro $a^{*}$ do xilema para o primeiro sistema e $a^{*}$ do floema para o segundo sistema, foram transformados por $\sqrt{x}$, enquanto que diâmetro do xilema, tipo de ombro, tipo de ponta, para o segundo sistema, e diâmetro de raiz para os dois sistemas, foram transformados por $\sqrt{x+0,50}$, para atender a pressuposição de normalidade de distribuição.

Posteriormente, foi realizada análise de variância conjunta, e análise de variância com informação entre e dentro de parcelas, para cada sistema, para os caracteres com interação genótipo $\mathrm{x}$ ambiente ou sem homogeneidade de variância na análise conjunta. Foram realizadas ainda análises de representatividade do número mínimo de famílias e de plantas para representar uma população de cenoura pelo método Bootstrap de simulação de subamostras com determinação baseada na estabilização da média e da variância genética. Para a estimação do número mínimo de plantas por parcela e de famílias, iniciouse com subamostras de duas plantas e cinco famílias, com incremento de uma planta e uma família, de uma análise para a outra. O número de plantas foi sucessivamente aumentado até se atingir o total de 20 plantas por parcela e de famílias até 100. Para cada tamanho de subamostra realizaram-se 20 


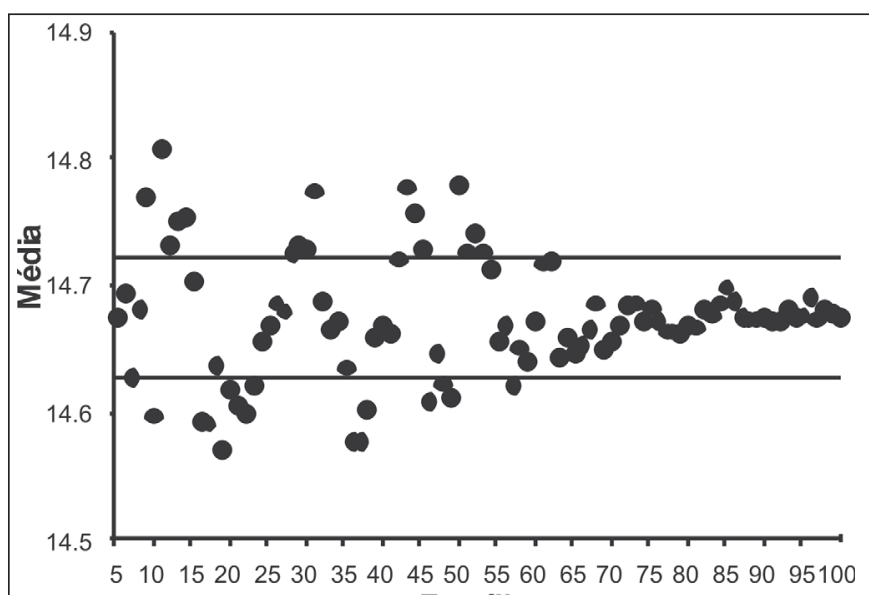

Famílias

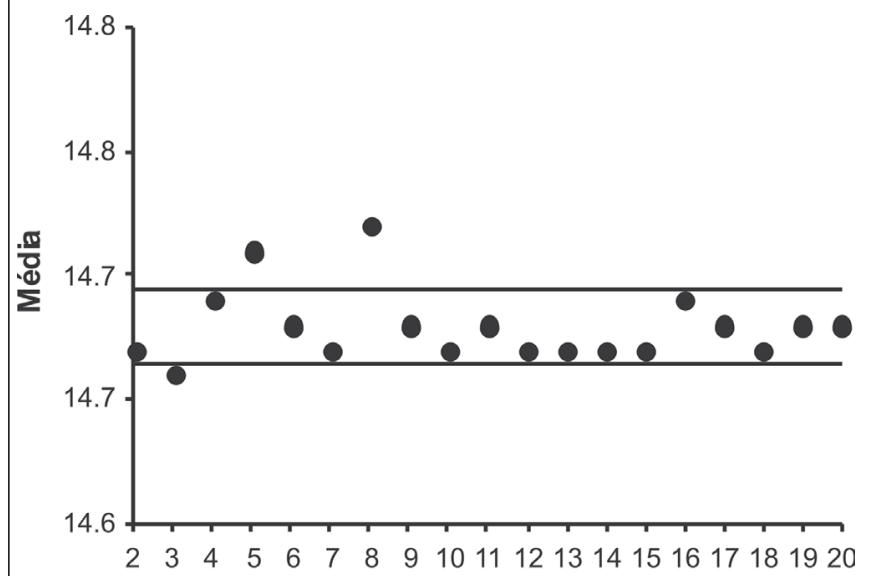

Plantas

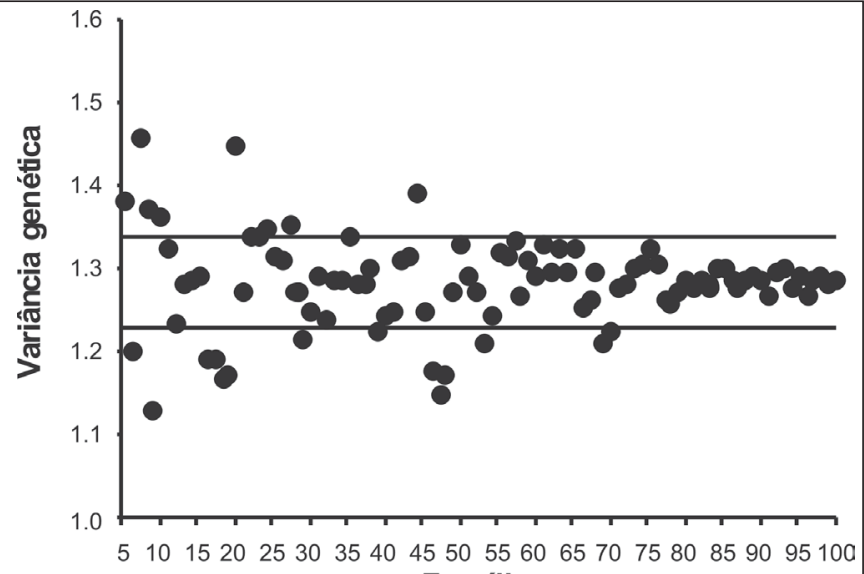

Famílias

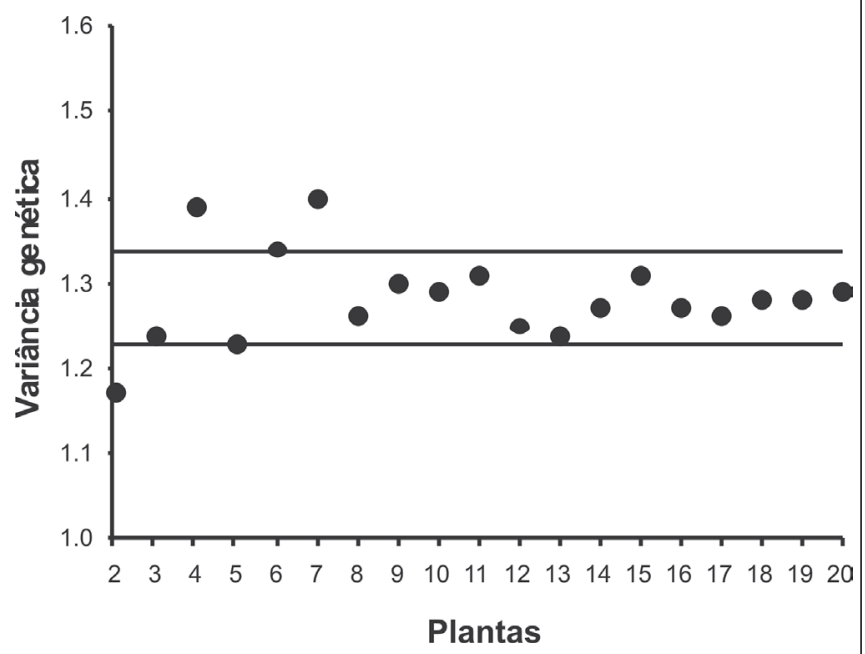

Figura 1. Número mínimo de famílias e de plantas dentro de parcela para uma população de cenoura por simulação de acordo com a estabilização da média e variância genética, para o caráter tamanho de raiz, cultivado em sistema de Agricultura Natural (minimum family number and plants per plot for a carrot population by simulation in accord with the average and genetic variance stabilizations, for the trait root size, cultivated in Natural Agriculture system). Brasília, Embrapa Hortaliças, 2007.

reamostragens de forma aleatória, com reposição. Para cada subamostra, foram estimados os parâmetros genéticos, obtendo-se em seguida a média das 20 subamostras do mesmo tamanho.

O número de plantas e de famílias, para representar a população, foi determinado como o ponto a partir do qual a estimativa do parâmetro escolhido tornou-se estável, de acordo com retas de limites superiores e inferiores do desvio padrão, tomando-se como referência a média obtida com as 20 plantas e 100 famílias, respectivamente, com objetivo de tornar as estimativas não subjetivas.

Todas as análises foram efetuadas utilizando-se o programa GENES (Cruz, 2006).

\section{RESULTADOS E DISCUSSÃO}

Pela análise de variância conjunta para os dois sistemas de cultivo, os caracteres massa, diâmetro de xilema e relação entre diâmetro de xilema, não possuem interação entre famílias e sistema de produção denotando homogeneidade de variância. Pela análise de variância conjunta, estes três caracteres (massa, diâmetro de xilema e relação entre diâmetro do xilema) foram significativos em diferenciar as famílias, e os coeficientes de variação foram de $21,32 \%, 17,31 \%$ e $17,81 \%$, respectivamente, indicando boa precisão experimental.

Para os caracteres comprimento de raiz, parâmetro a* de xilema e de floema, tipo de ponta e tipo de ombro, a interação de famílias x sistema de produção foi significativa, e diâmetro de raiz sem homogeneidade das variâncias residuais, indicando que os ambientes não influenciaram da mesma forma na expres- são destes caracteres, sendo que para estes, as inferências foram efetuadas para cada sistema.

Pela análise de variância dos dados do sistema Agricultura Natural, verificou-se que todos os caracteres foram significativos em diferenciar as famílias, exceto para o parâmetro a* do floema. Os coeficientes de variação ambiental foram reduzidos, sendo inferiores a $13 \%$ para todos os caracteres, indicando boa precisão experimental. Já, pela análise de variância para o sistema Agricultura Orgânica, verificou-se que apenas o caráter diâmetro de raiz não foi significativo na diferenciação das famílias, revelando forte influência ambiental, com coeficiente de variação de $38,50 \%$. Para os demais caracteres, as estimativas de coeficiente de variação foram inferiores a $9 \%$.

Para o caráter comprimento de raiz, no sistema Agricultura Natural, de acor- 
do com o método da estabilização da média e da variância genética, o primeiro ponto de uma série constante que esteve dentro do limite do desvio padrão variou de 8 para a estabilização da média, a 7 para a estabilização da variância genética, indicando que 8 deve ser considerado como a estimativa do número mínimo de plantas por parcela para representar uma população, em condições de campo, para este caráter (Figura 1). Números superiores a estes não acrescentariam maiores informações e não proporcionariam redução significativa do erro (Zanon \& Storck, 2000).

Ainda para o sistema de cultivo Agricultura Natural, em relação ao número mínimo de famílias, verifica-se que a estabilização da média e da variância genética, dentro de um desvio padrão, também para o caráter comprimento de raiz, o primeiro ponto de uma série constante dentro dos limites de confiança, é correspondente a 58 famílias, e para a variância genética a 70 famílias. Portanto, para este caráter, o número estimado mínimo de famílias deve ser de 70 (Figura 1). Para os demais caracteres nos dois sistemas de cultivo agroecológicos, as estimativas de número mínimo de plantas por parcela e de famílias foi realizado seguindo este mesmo modelo, e estão descritos nas Tabelas 1 e 2 .

Há que se acrescentar que ainda em relação ao caráter comprimento de raiz, no sistema de cultivo Agricultura Orgânica, verificou-se que 63 seria o número mínimo de famílias a ser utilizado em ensaios para a seleção de famílias (Tabela 1).

Para os demais caracteres que expressaram interação entre famílias x sistema de cultivo, ou ausência de homogeneidade de variância, verificouse que o número mínimo de 74 famílias que deve ser utilizado na avaliação conjunta dos caracteres: diâmetro de raiz, parâmetro a* do xilema, tipo de ponta e tipo de ombro no sistema de cultivo Agricultura Natural. Da mesma forma, para os caracteres $a^{*}$ do xilema e floema e ainda tipo de ponta e de ombro, avaliados no sistema de cultivo Agricultura Orgânica, este valor também foi de no mínimo 74 famílias (Tabela 1). Em relação ao número mínimo estimado de plantas por parcela, para a avaliação destes mesmos caracteres, pode-se verificar

Tabela 1. Estimativas do número mínimo de famílias e de plantas por parcela, por simulação, de acordo com a estabilização da média e variância genética, para caracteres de raiz de cenoura que apresentaram interação genótipo x ambiente ou não apresentaram homogeneidade de variância na análise de variância conjunta, em uma população com 100 famílias e 20 plantas por parcelas em duas repetições, cultivada em dois sistemas de produção agroecológicos (estimates of the minimum family number and of plants per plot, by simulation, in accord with the mean and genetic variance stabilizations, for traits of carrot root that presented interaction genotype $\mathrm{x}$ environment and variance homogeneity in the joint variance analysis, in a population with 100 families and 20 plants per plot in two replications, cultivated in two systems of agroecologic production) Brasília, Embrapa Hortaliças, 2007.

\begin{tabular}{|c|c|c|c|c|c|}
\hline \multirow{2}{*}{ Caráter } & \multicolumn{2}{|c|}{ Agricultura Natural } & \multicolumn{2}{|c|}{ Agricultura orgânica } & \multirow{2}{*}{ Valor Médio } \\
\hline & Média & Variância & Média & Variância & \\
\hline \multicolumn{6}{|c|}{ Número de famílias } \\
\hline Comprimento & 58 & 70 & 57 & 63 & 58,75 \\
\hline Diâmetro Raiz (DR) & 68 & 72 & -1 & - & 70,00 \\
\hline$a^{*}$ Xilema & 60 & 67 & 59 & 68 & 63,50 \\
\hline$a^{*}$ Floema & - & - & 61 & 71 & 66,00 \\
\hline Tipo ponta & 54 & 52 & 62 & 74 & 60,50 \\
\hline Tipo ombro & 60 & 74 & 68 & 58 & 65,00 \\
\hline \multicolumn{6}{|c|}{ Número de plantas por parcela } \\
\hline Comprimento & 9 & 8 & 13 & 8 & 9,50 \\
\hline Diâmetro Raiz (DR) & 11 & 7 & - & - & 9,00 \\
\hline$A^{*}$ Xilema & 17 & 6 & 18 & 11 & 13,00 \\
\hline$A^{*}$ Floema & - & - & 11 & 5 & 8,00 \\
\hline Tipo ponta & 13 & 13 & 5 & 8 & 9,75 \\
\hline Tipo ombro & 8 & 10 & 11 & 16 & 11,25 \\
\hline
\end{tabular}

${ }^{1}$ Não significativo pela análise de variância ( ${ }^{1}$ not significant by variance analyses).

Tabela 2. Estimativas do número mínimo de famílias e de plantas por parcela, por simulação, de acordo com a estabilização da média e variância genética, para caracteres de raiz de cenoura que não apresentaram interação genótipo x ambiente e apresentaram homogeneidade de variância na análise de variância conjunta, em uma população com 100 famílias e 20 plantas por parcelas em duas repetições, cultivada em dois sistemas de produção agroecológicos (estimates of the minimum family number and of plants per plot, by simulation, in accord with the mean and genetic variance stabilizations, for traits of carrot root that didn't present interaction genotype $\mathrm{x}$ environment and presented variance homogeneity in the joint variance analysis, in a population with 100 families and 20 plants per plot in two replications, cultivated in two systems of agroecologic production). Brasília, Embrapa Hortaliças, 2007.

\begin{tabular}{|c|c|c|c|}
\hline \multicolumn{4}{|c|}{ Agricultura Natural e Agricultura orgânica } \\
\hline \multirow{2}{*}{ Caráter } & Média & Variância & \multirow{2}{*}{ Valor Médio } \\
\hline & \multicolumn{2}{|c|}{ Número de famílias } & \\
\hline Massa & 65 & 56 & 60,50 \\
\hline Diâmetro xilema (DX) & 65 & 55 & 60,00 \\
\hline Relação DR/DX & 58 & 63 & 60,50 \\
\hline \multicolumn{4}{|c|}{ Número de plantas por parcela } \\
\hline Massa & 16 & 9 & 12,50 \\
\hline Diâmetro xilema (DX) & 5 & 16 & 10,50 \\
\hline Relação DR/DX & 10 & 11 & 10,50 \\
\hline
\end{tabular}

${ }^{1}$ Não significativo pela análise de variância ( ${ }^{1}$ not significant by variance analyses).

que pelo menos 17 plantas necessitam ser avaliadas no sistema Agricultura Natural; já para Agricultura Orgânica, este valor é de 18 (Tabela 1).

Para os caracteres sem interação família x sistema de cultivo, ou ausência de homogeneidade de variância (massa, diâmetro de xilema e relação entre diâmetro de xilema e diâmetro da raiz), o número mínimo estimado de famílias, para os dois sistemas de produção, foi de 65 , enquanto 16 foi o número mínimo 
de plantas (Tabela 2).

Tem-se, portanto, que para que todos os caracteres avaliados possam ser avaliados nos dois sistemas de produção, o número de famílias mínimo requerido é 74 , enquanto a parcela deveria conter pelo menos 18 plantas. Estes valores seriam suficientes para propiciar adequada avaliação e ou caracterização das famílias em teste.

Estes valores de número mínimo de famílias foram superiores aos estimados por Vieira et al. (2006) para os caracteres número e comprimento de folhas, massa e comprimento da raiz e primeira contagem e germinação de sementes, que foi de 67. Granate et al. (2001) utilizaram também o método de análise visual dos gráficos e verificaram que o número mínimo de famílias, em população de milho pipoca 'CMS 43', foi de 141.

Desta forma, pode-se verificar que uma amostra de 18 plantas competitivas/ parcela, coletada em ensaios com duas repetições, em 74 famílias de meio-irmãos são suficientes para garantir uma adequada avaliação desta estrutura populacional em cenoura para os caracteres estudados.

\section{REFERÊNCIAS}

ALVES SMF; SERAPHIN JC. 2004. Coeficiente de heterogeneidade do solo e tamanho de parcela. Pesquisa Agropecuária Brasileira 39: 105-111.

CRUZ CD. 2006. Programa Genes: Biometria. Viçosa: Editora UFV, 382p.

EBERHART SA. 1970. Factors affecting efficiencies of breeding methods. African Soils 15: 669-680.

FREITAS JA; SILVA EB; FALLIERI J; LANZA MA; FARIA RS; SILVA PJ. 2001. Tamanho de amostra na parcela para caracterização da altura de plantas de algodoeiro herbáceo Gossypium hirsutum. Ciência Rural 31: 583-587.

GRANATE MJ; CRUZ CD; PACHECO CAP. 2001. Número mínimo de famílias de meios-irmãos para representar uma população de milho-pipoca. Revista Ceres 48: 209-221.

GRAYBILL FA; KNEEBONE WR. 1959. Determining minimum populations size for initial evaluation of breeding material. Agronomy Journal 51: 4-6.

PALOMINO EC; RAMALHO MAP; FERREIRA DF. 2000. Tamanho da amostra para avaliação de populações de meiosirmãos de milho. Pesquisa Agropecuária Brasileira 35: 1433-1439.
PEREIRA AS. 2002. Teores de carotenóides em cenoura (Daucus carota L.) e sua relação com a coloração das raízes. Viçosa: UFV. 128p. (Tese doutorado).

SOUZA JL. 2006. Manual de horticultura orgânica. 2.ed. atualizado e ampliado. Viçosa: UFV. 843p.

STEEL RGD; TORRIE JH. 1960. Principles and procedures of statistics. New York: McGraw-Hill. 841p.

STORCK L; BISOGNIN DA; OLIVEIRA SJR. 2006. Dimensões dos ensaios e estimativas do tamanho ótimo de parcela em batata. Pesquisa Agropecuária Brasileira 41: 903909.

VIANA AES; SEDIYAMA T; CECON PR; LOPES SC; SEDIYAMA MAN. 2002. Estimativas de tamanho de parcela em experimentos com mandioca. Horticultura Brasileira 20: 58-63.

VIEIRA JV; NASCIMENTO WM; SILVA JBC. 2006. Número mínimo de populações de meios-irmãos para avaliação de uma população de cenoura. Pesquisa Agropecuária Brasileira 41: 365-367.

ZHANGA R; WARRICK AW; MYER DE. 1994. Heterogeneity, plot shape effect and optimum plot size. Geoderma 62: 183-197.

ZANON MLB; STORCK L. 2000. Tamanho ótimo de parcelas experimentais para Eucalyptus saligna Smith. em dois estádios de desenvolvimento. Cerne 6: 104-111.

WU KK; HEINZ DJ; MEYER HK; LADD SL. 1978. Minimum sample size for estimating progeny mean and variance. Crop Science 18: 57-62. 